\title{
Thermodynamic Analysis of Combined Cooling Heating and Power System with Absorption Heat Pump Based on Small Modular Lead-based Reactor
}

\author{
Han Wang ${ }^{1,2}$, Dali Yu ${ }^{1 *}$, Chi Xu ${ }^{1,2}$, Muhammad Salman Khan ${ }^{l}$ and Yunqing Bai ${ }^{1}$ \\ ${ }^{1}$ Key Laboratory of Neutronics and Radiation Safety, Institute of Nuclear Energy Safety Technology, Hefei Institutes of Physical Science, \\ Chinese Academy of Sciences, Hefei 230031, China \\ ${ }^{2}$ University of Science and Technology of China, Hefei 230026, China
}

\begin{abstract}
Small Modular Lead-based Reactor (SMLR) has generated great interest in academic research all around the world due to its good safety characteristics and relatively high core outlet temperature. In this paper, a Combined Cooling Heating and Power (CCHP) system with usage of absorption heat pump, which couples with a SMLR, was proposed to fulfill the energy demands in remote areas. Thermodynamic analysis was implemented to improve the performance of the CCHP system based on SMLR. To meet the remote areas' energy needs, the main parameters and mass flow rate of a $35 \mathrm{MW}_{\text {th }}$ SMLR design were analyzed. The SMLRCCHP with absorption heat pump system can provide electric power $12.5 \mathrm{MW}_{\mathrm{e}}$, heating $9.5 \mathrm{MW}_{\mathrm{h}}$, and cooling $2.54 \mathrm{MW}_{\mathrm{c}}$. The total energy utilization efficiency of the system can be $69.12 \%$. This work can provide a reference in the design and optimization of the CCHP system to meet the energy demands in the remote areas.
\end{abstract}

\section{Introduction}

The Lead-based Fast Reactor is expected to firstly achieve the industrial demonstration and commercial application in all of the fourth-generation nuclear power systems. Compared to other nuclear power systems, the coolant in the Small Modular Lead-based Reactor (SMLR) is chemically inert, the system operates at atmospheric pressure. Therefore, it has the characteristic of high security. Liquid alloy has very good heat transfer ability, the layout is compact and flexible, which makes the SMLR-based Combined Cooling Heating and Power (CCHP) system flexible in the site selection [1]. The system is suitable for a variety of complex geographic environments. The refueling cycle of SMLR is close to ten years, which makes it more sustainable and stable than other prime movers for CCHP systems. Besides, the high coolant outlet temperature can achieve high energy utilization, which well applies for remote areas [2].

There are some researches on the SMLR comprehensive utilization systems. Up to now, the existing studies about SMLR are only in the initial stage, there is no mature design of SMLR-CCHP. Institute of Nuclear Energy Safety Technology (INEST), the Chinese Academy of Sciences (CAS) carried out the concept design development of CCHP system driven by SMLR. Khan [3] proposed the conceptual design of a new double reheat high-efficiency power generation system and carried out parameter optimization analysis. Xu [4] proposed a preliminary design of the cogeneration system for SMFR with the extraction-condensing and back- pressure cogeneration type, pointing out the optimization direction of system integration for the Lead-cooled Fast Reactor. Existing researches focus on to improve the electricity/power generation and heating efficiency.

As an energy-saving technology, absorption heat pump is widely used in low temperature waste heat utilization. It uses a small amount of high temperature heat source (such as steam, high temperature hot water, combustible gas combustion heat, etc.) as the driving heat source to produce a large amount of useful heat energy at medium temperature then improve the efficiency of heat energy utilization [5]. The SMLR system discharges large amounts of low-temperature cooling water with abundant low-level energy. Lithium bromide absorption heat pump can use this low-level energy and convert it into usable high level heat energy [6]. Li [7] proposed a new type of district heating method based on Co-ah cycle and designed to improve both the capacity of heating system and the energy efficiency of Cogeneration plant. Zhao [8] developed a theoretical model of the $\mathrm{LiBr}-\mathrm{H}_{2} \mathrm{O}$ absorption heat pump system, and simulated the thermodynamic cycle of the heat pump system, indicating that COP and pyrotechnic efficiency can be used for performance analysis of absorption heat pumps.

This paper designs CCHP systems with absorption heat pump based on SMLR for remote areas. Thermodynamic calculations are performed to analyze the parameters for the second circuit and study the effect of drive steam, outlet temperature of the hot water on the efficiency of the absorption heat pump. Derive the efficiency of the CCHP system at the optimal parameters. This work can provide a reference in the design and

$\overline{{ }^{*} \text { Corresponding author: dlyu@inest.cas.cn }}$ 
optimization of the SMLR-CCHP for remote areas.

\section{Materials and Methods}

\subsection{Design parameters of SMLR}

We have proposed the SMLR with 35MW because of its ultra-small and high-efficiency technical characteristics. The main design parameters of the SMLR for the CCHP are listed in Table 1.

Table 1. Main parameters of the SMLR

\begin{tabular}{|c|c|}
\hline Parameters & Value \\
\hline $\begin{array}{c}\text { Reactor Thermal } \\
\text { Power, } \mathrm{MW}_{\text {th }}\end{array}$ & 35 \\
\hline $\begin{array}{c}\text { Lead In/Out } \\
\text { Temperature from } \\
\text { Core, }{ }^{\circ} \mathrm{C}\end{array}$ & $375 / 495$ \\
\hline $\begin{array}{c}\text { Water In/Steam } \\
\text { Out Temperature } \\
\text { from } \mathrm{SG},{ }^{\circ} \mathrm{C}\end{array}$ & $340 / 470$ \\
\hline $\begin{array}{c}\text { Secondary Cycle } \\
\text { Pressure, } \mathrm{MPa}\end{array}$ & 16.0 \\
\hline
\end{tabular}

The maximum electricity, cooling and heating demand is shown in Table 2.

Table 2. Energy demands of the remote areas

\begin{tabular}{|c|c|c|c|}
\hline & $\begin{array}{c}\text { Electricity } \\
\text { (MW) }\end{array}$ & $\begin{array}{c}\text { Heating } \\
\text { (MW) }\end{array}$ & $\begin{array}{c}\text { Cooling } \\
\text { (MW) }\end{array}$ \\
\hline Value & 12 & 9 & 2 \\
\hline
\end{tabular}

Some assumptions on parameters are given as shown in Table 3, including the turbine efficiency, absorption chillers efficiency, and heater efficiency.

Table 3. Assumed fundamental parameters

\begin{tabular}{|c|c|}
\hline Parameters & Value \\
\hline $\begin{array}{c}\text { Isentropic } \\
\text { efficiency of HP } \\
\text { turbine }\end{array}$ & 0.8 \\
\hline $\begin{array}{c}\text { Isentropic } \\
\text { efficiency of LP } \\
\text { turbine }\end{array}$ & 0.7 \\
\hline $\begin{array}{c}\text { Absorption chills } \\
\text { COP }\end{array}$ & 1.1 \\
\hline Heater efficiency & 0.95 \\
\hline
\end{tabular}

\subsection{Design of CCHP system based on SMLR}

The CCHP system usually consists of a power generation system, heat recovery system and cooling system. The SMLR is used as the thermal power source for the CCHP system. Heating is mainly used to supply the hightemperature industrial steam and domestic hot water. The cooling system has two forms: steam absorption chiller and electric compression chiller. The steam outlet temperature of LP turbine is appropriate for a doubleeffect absorption chiller [9].

The steam at the outlet of the second circuit is mainly divided into three parts. i) steam works in the HP and LP turbines, then convert mechanical energy into electrical energy, ii) steam at HP turbine exit is taken out and used to supply the heating for the residents iii) steam from the LP turbine heated exchange with the double absorption chiller to meet the cooling demand. The schematic of SMLR-CCHP is shown in Fig. 1.

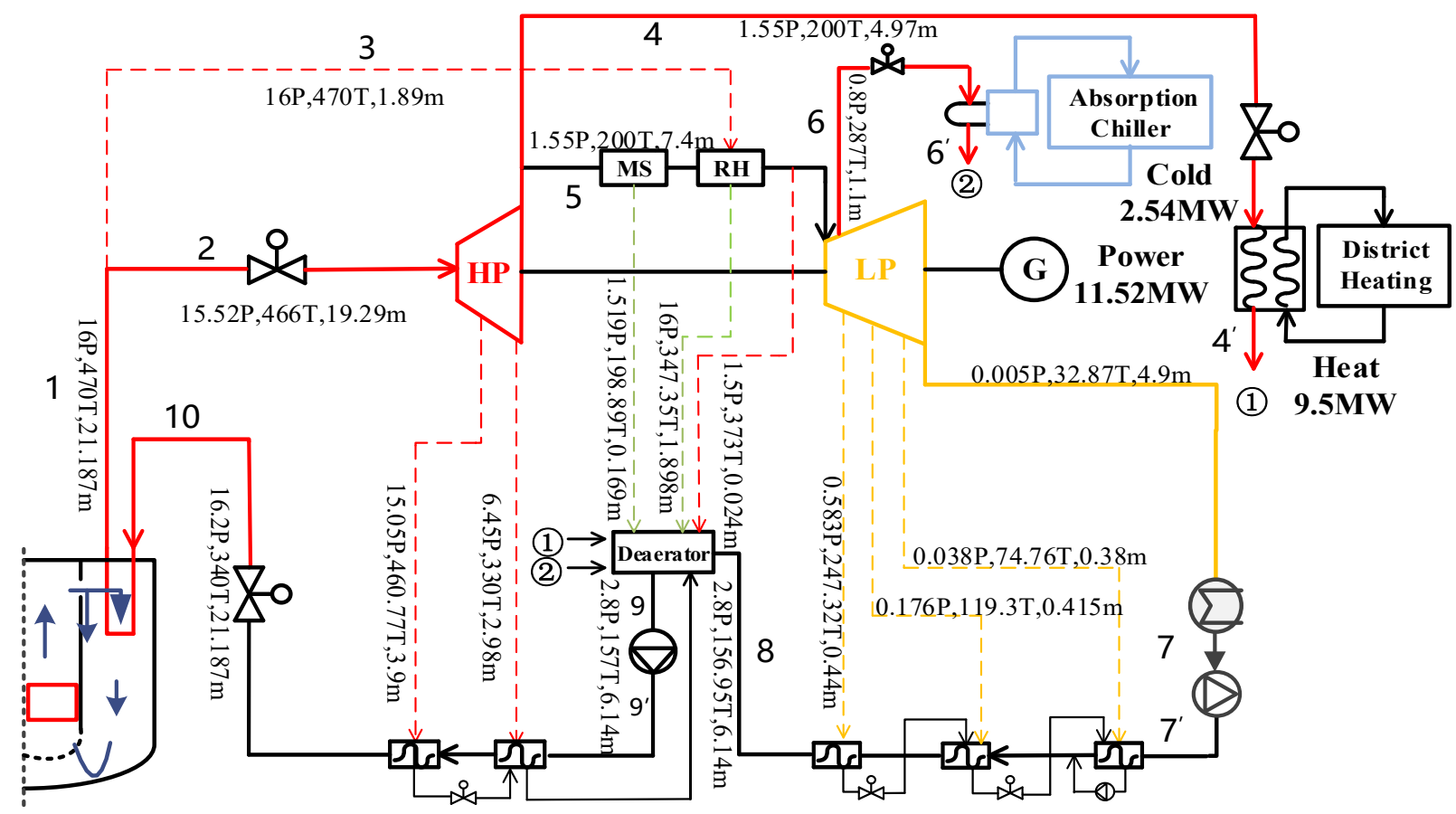

Fig. 1. Schematic design of the SMLR-CCHP Note: $\mathrm{P}(\mathrm{MPa}), \mathrm{T}\left({ }^{\circ} \mathrm{C}\right), \mathrm{m}\left(\mathrm{kg} \cdot \mathrm{s}^{-1}\right)$ 
The main parameters of cold, heat and electricity supply are shown in Table 4

Table 4. The main parameters of cold, heat and electricity

\begin{tabular}{|c|c|}
\hline Parameters & Value \\
\hline $\begin{array}{c}\text { Reactor Thermal } \\
\text { Power, } \mathrm{MW}_{\text {th }}\end{array}$ & 35 \\
\hline Power, $\mathrm{MW}_{\mathrm{e}}$ & 11.52 \\
\hline Heating, MW & 9.5 \\
\hline Cooling, $\mathrm{MW}_{\mathrm{c}}$ & 2.54 \\
\hline Pump, MW & 0.37 \\
\hline Efficiency, \% & 66.26 \\
\hline
\end{tabular}

Although the temperature of the steam at the outlet of the LP turbine is $32.87^{\circ} \mathrm{C}$, the mass flow rate of the steam is up to $4.9 \mathrm{~kg} / \mathrm{s}$, the steam has a large amount of usable heat. The energy of the steam will be wasted if cooled by air in condenser directly. Absorption heat pump can make the full use of the low-temperature waste heat from the condenser [10]. To improve the utilization of lowtemperature waste heat from SMLR-CCHP, it is necessary to optimize the parameters for better performance.

\subsection{Thermodynamic model of SMLR-CCHP and absorption heat pump}

The thermodynamic model is carried out for the system. Thermodynamic model of the system is based on the conservation of mass, energy, and momentum [11]. The parametric calculation of the SMLR-CCHP needs to be considered the mass flow rate, temperature, and enthalpy at each point of the system based on the pressure.

The power produced by the HP and LP turbines of the SMLR-CCHP as follows:

$$
W_{p}=W_{h p}+W_{l p}
$$

The cooling process:

$$
W_{c}=m_{6} \cdot\left(h_{6}-h_{6}\right)
$$

The heating process:

$$
W_{h}=m_{4} \cdot\left(h_{4}-h_{4}\right)
$$

The compression process:

$$
W_{c p}=m_{7} \cdot\left(h_{7}-h_{7}\right)+m_{9}\left(h_{9}-h_{9^{\prime}}\right)
$$

Thermal efficiency of the system:

$$
\eta_{t}=\left(W p+W_{c}+W h-W c p\right) / Q_{c o r}
$$

\subsection{Schematic Flow Chart and Thermodynamic model of Absorption Heat Pump}

Absorption heat pump mainly contains Evaporation, Absorber, Generator, Condenser four parts [12]. The basic principle is to utilize the difference in absorption characteristics between concentrated and dilute solutions of lithium bromide, recycling parts of the waste heat from condensate [13]. Schematic flowchart of the absorption heat pump shown in the Fig.2.

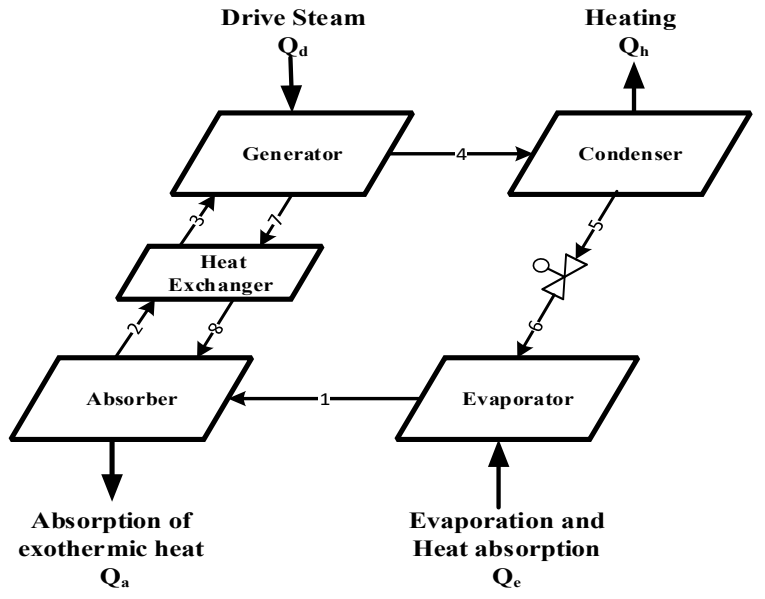

Fig. 2. Schematic flowchart of the absorption heat pump

Four basic parameters are set during the cycling of the lithium bromide absorption heat pump, driving the heat source at a pressure of $0.4 \mathrm{MPa}$. Condensate temperature is $32.87^{\circ} \mathrm{C}$, The inlet/outlet temperature of the water for heating is $60 / 80{ }^{\circ} \mathrm{C}$.

The system makes full use of the low-temperature waste heat from the condenser to supply energy for the remote areas. To study the additional heating brought by absorption heat pump, the system maintains the same heating capacity and cooling capacity as the original system. Compared with the original system, lowtemperature steam at the condenser not cooled by the air directly but exchange the heat with the absorption heat pump. 


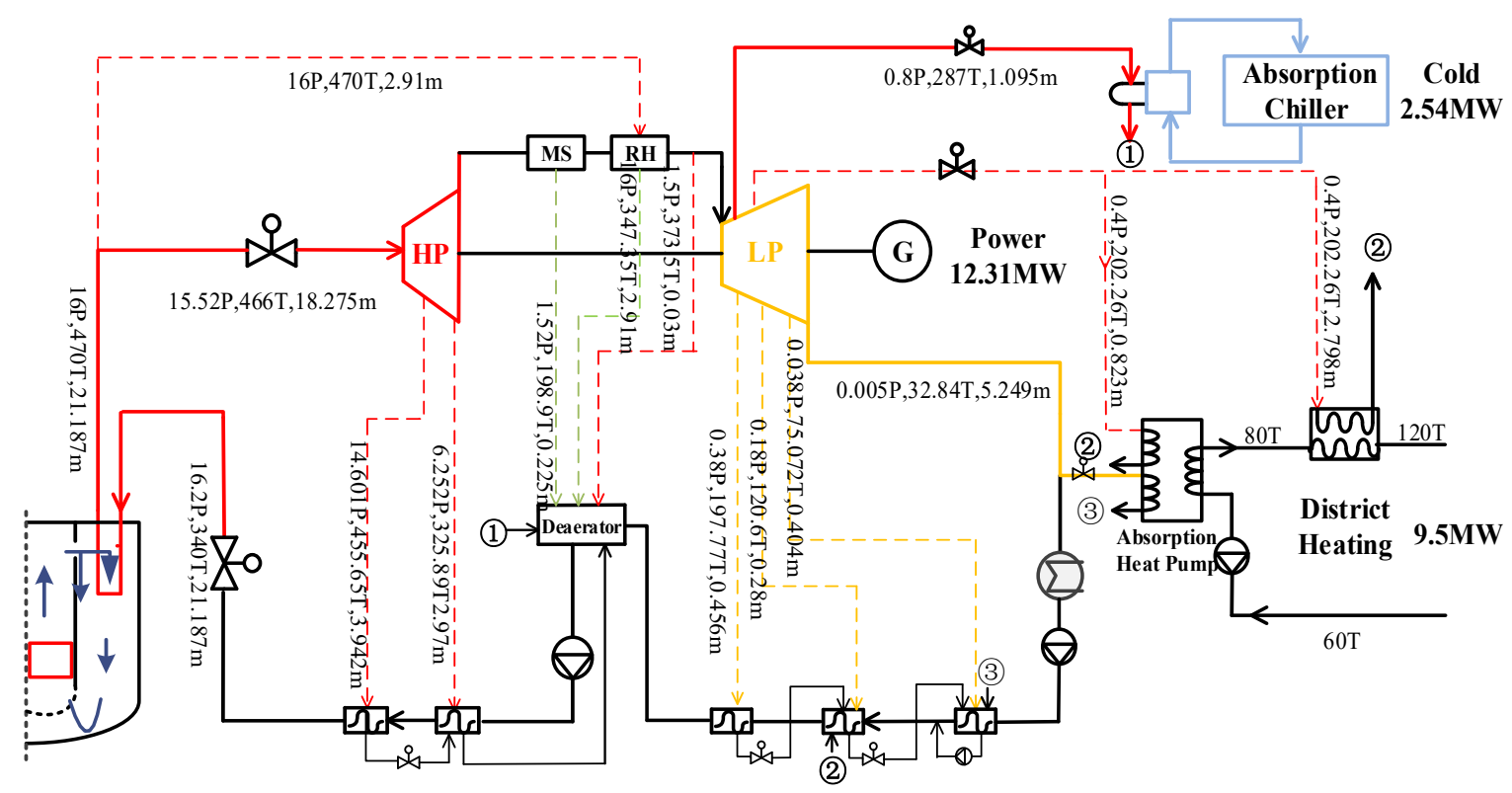

Fig. 3. Schematic design of the SMLR-CCHP with heat pump

\section{Results \& Discussion}

By introducing absorption heat pump, a large amount of low-temperature waste heat from LP turbine exhaust can be fully utilized. Compared with origin system, it provides theoretically an additional power of $1.04 \mathrm{MW}_{\mathrm{e}}$. The SMLR-CCHP system can provide electric power 12.56 $\mathrm{MW}_{\mathrm{e}}$, cooling $2.54 \mathrm{MW}_{\mathrm{c}}$ and heating $9.5 \mathrm{MW}_{\mathrm{h}}$. The energy utilization rate of the system can be up to $69.2 \%$ by the addition of absorption heat pump. The parameters are shown in Table 5

Table 5. The SMLR-CCHP with absorption heat pump parameters

\begin{tabular}{|c|c|}
\hline Parameters & Value \\
\hline $\begin{array}{c}\text { Reactor Thermal } \\
\text { Power, } \mathrm{MW}_{\text {th }}\end{array}$ & 35 \\
\hline $\begin{array}{c}\text { Driving Pressure, } \\
\mathrm{MPa}\end{array}$ & 0.4 \\
\hline $\begin{array}{c}\text { Inlet/Outlet hot } \\
\text { water }\end{array}$ & $60 / 80$ \\
\hline $\begin{array}{c}\text { Condensate } \\
\text { Water, }{ }^{\circ} \mathrm{C}\end{array}$ & 32.84 \\
\hline $\begin{array}{c}\text { Heat pump, COP } \\
\text { Power, MW }\end{array}$ & 1.71 \\
\hline Heating, MWh & 12.56 \\
\hline Cooling, MW & 9.5 \\
\hline Pump, MW & 2.54 \\
\hline Efficiency, \% & 0.39 \\
\hline
\end{tabular}

\section{Conclusions}

The overall thermal performance of the CCHP system based on SMLR is calculated. The thermal performance of the CCHP system with the heat pump is higher than the system without the heat pump. At the same cooling capacity and heating capacity, the generating power capacity increases from $11.52 \mathrm{MW}$ to $12.56 \mathrm{MW}$. SMLRCCHP system with addition of absorption heat pump is suitable to meet the energy demands in the remote areas.

\section{Acknowledgments}

This work was supported by the Key Research Program of the Chinese Academy of Sciences (Grand No. ZDRW-KT2019-1-0202) and the National Natural Science Foundation of China Program (U1967204)

\section{References}

1. A, S. S. , A, S. Z. , A, M. M. , \& B, R. S. ., 2019. Nuclear power as foundation of a clean energy future: a review. Energy Procedia. 160, 513-518.

2. Liu, W., Zhang, G., Wang, L., Zhou, T.J.N.E., 2019. Thermal-hydraulic transient characteristics analysis of Small Lead-based Reactor from natural circulation to forced circulation. NUCL SCI ENG. 34,38-47.

3. Khan, M.S., Bai, Y., Huang, Q., Xu, C., Wang, L.J.A.T.E., 2019. Conceptual design and optimization of power generation system for Lead-based Reactor. APPL THERM ENG. 168:114714.

4. Xu, C., Li, Y., Jin, M., Kong, F., Bai, Y.J.A.T.E., 2020. Preliminary design and analysis on the cogeneration system for Small Modular Lead-cooled Fast Reactor. APPL THERM ENG. 174:115302.

5. B, Z.Y.X.A., B, J.T.G.A., C, H.C.M., C, D.S.L., B, R.Z.W.A.J.E.C., 2020. Double-section absorption 
heat pump for the deep recovery of low-grade waste heat. ENERG CONVERS MANAGE. 220:113072.

6. Cao, X.Q., Yang, W.W., Zhou, F., He, Y.L.J.A.T.E., 2014. Performance analysis of different hightemperature heat pump systems for low-grade waste heat recovery. APPL THERM ENG. 438-447.

7. Li, Y., Fu, L., Zhang, S., Jiang, Y., Zhao, X.J.E.C., Management, 2011. A new type of district heating method with co-generation based on absorption heat exchange (co-ah cycle). ENERG CONVERS MANAGE. 52, 1200-1207.

8. Zhao, Z.C., Zhao, J.W.J.J.o.D.U.o.T., 2008. Analysis of thermodynamic performance of combined ejection-absorption heat pump with $\mathrm{LiBr}-\mathrm{H}_{2} \mathrm{O}$. J. Dalian Univ. Technol. 48, 480-485.

9. Cho, H., Smith, A.D., Mago, P.J.A.E., 2014. Combined cooling, heating and power: A review of performance improvement and optimization. APPL ENERG. 136, 168-185.

10. Zhang, H., Li, Z., Zhao, H.J.E.C., Management, 2015. Thermodynamic performance analysis of a novel electricity-heating cogeneration system (EHCS) based on absorption heat pump applied in the coalfired power plant. ENERG CONVERS MANAGE. 105, 1125-1137.

11. Liu, W., Zhang, G., Wang, L., Zhou, T.J.N.E., 2019. Thermal-hydraulic transient characteristics analysis of Small Lead-based.

12. Zheng, S., Xie, X., Yi, J.J.I.J.o.R., 2016. Experimental study on the flash evaporation process of $\mathrm{LiBr}-\mathrm{H}_{2} \mathrm{O}$ solution in an absorption heat pump. INT J REFRIG. 61, 117-126.

13. Ling, C., Jing, Z., Lu, J., Kecheng, L., Wenquan, T.J.J.o.R., 2019. Thermodynamic analysis of LiBr$\mathrm{H}_{2} \mathrm{O}$ absorption heat pump. INT J REFRIG. 32,94-96. 